Rua Marquês de São Vicente, 225 - sala F512

22451-045 - Rio de Janeiro - R sergio_barra@puc-rio.br

\section{A IMPRESSÃO RÉGIA DO RIO DE JANEIRO E A CRIAÇÃO DO NOVO IMPÉRIO PORTUGUÊSNA AMÉRICA}

\author{
Sérgio Hamilton da Silva Barra* \\ Pontifícia Universidade Católica do \\ Rio de Janeiro \\ Rio de Janeiro - Rio de Janeiro - Brasil
}

\title{
Resumo
}

O presente artigo busca analisar o papel político exercido pela Impressão Régia do Rio de Janeiro no contexto da instalação da Corte portuguesa na América. Herdeira das tipografias criadas no Reino no final do século XVIII, no âmbito do projeto reformista ilustrado português, a Impressão Régia do Rio de Janeiro preservava a função pragmática de impressão e divulgação dos saberes úteis ao desenvolvimento do Império, que caracterizava tipografias como a do Arco do Cego, criada em 1799. Baseada em um modelo ilustrado de conhecer para intervir na realidade, fazia da difusão das Luzes no Império português uma função não apenas cultural, mas também política. Frente às tensões políticas que a nova situação criada pela mudança da sede do Império gerava, a Impressão Régia desempenhou o importante papel de legitimação e sustentação do projeto político de criação de um novo Império português na América, longamente acalentado por letrados e estadistas ilustrados portugueses. Busca-se, dessa forma, chamar a atenção para a relação intrínseca entre saber e poder no reformismo ilustrado português.

\section{Palavras-chave}

Império português - Ilustração - imprensa.

Doutor em História Social da Cultura (PUC-Rio, 2012), professor do Departamento de História do Centro de Ciências Sociais da Pontifícia Universidade Católica do Rio de Janeiro. 


\section{Contact}

Rua Marquês de São Vicente, 225 - sala F5 12 22451-045 - Rio de Janeiro - RJ sergio_barra@puc-rio.br

\section{THE IMPRESSÃO RÉGIA DO RIO DE JANEIRO AND THE MAKING OF THE NEW PORTUGUESE EMPIRE IN AMERICA}

\author{
Sérgio Hamilton da Silva Barra \\ Pontifícia Universidade Católica do \\ Rio de Janeiro \\ Rio de Janeiro - Rio de Janeiro - Brazil
}

\begin{abstract}
This paper analyzes the political role played by the Impressão Régia do Rio de Janeiro in the context of the installation of the Portuguese court in America. Heir of typographies created in the kingdom in the late eighteenth century, under the Portuguese enlightened reformist project, the Impressão Régia do Rio de Janeiro preserves the pragmatic function of print and dissemination of useful knowledges for the development of the Empire, which characterized typographies such as Arco do Cego, created in 1799. Based on an enlightened model of knowing to intervening in reality, made the dissemination of the Lights in the Portuguese empire not only a cultural but also a political function. In the face of the political tensions that were caused by the new situation created by the Empire seat moving, the Impressão Régia do Rio de Janeiro has played an important role in legitimizing and sustaining of the political project of a new Portuguese Empire creation in America, a long cherished by enlightened Portuguese scholars and statemen. Seeking, thereby, highlight the intrinsic relationship between culture and power in the Portuguese enlightened reformism.
\end{abstract}

\title{
Keywords
}

Portuguese Empire - Enlightenment - press. 


\section{A Ilustração como projeto político}

Em 1809, a recém-criada Impressão Régia do Rio de Janeiro publicou uma Memória sobre as salitreiras naturais de Monte Rorigo, de autoria de José Vieira Couto (1752-1827), escrita originalmente em 1803. A intenção do autor era dar notícia de uma salitreira descoberta nas serras de Minas Gerais de onde era possível extrair nitrato de potássio, utilizado na fabricação de pólvora, o que fez com muita personalidade, ao compor um diálogo ficcional entre dois viajantes, em que se previa um glorioso futuro para a exploração do salitre naquela localidade:

Parece-me já lobrigar, por entre o escuro e anuviado espaço do futuro, dois viajeiros que param defronte do Monte Rorigo, que pasmam em suas máquinas e casarias e metem prática desta maneira: - Amigo, que elevado monte é este? Que querem dizer estes vastos edifícios? Que estrondo é este que tanto atroa os meus ouvidos? Que espesso fumo em rolos ofusca os ares? Que risonhas povoações são estas, que rega este grande e manso rio? - Monte Rorigo é o nome desta montanha, lhe responde o companheiro, aqui se fabrica a maior parte do salitre do Reino, toda esta povoação que se estende ao longo deste rio é a feliz Ribeira de Monte Rorigo. ${ }^{1}$

O diálogo criado pelo autor nos permite ver também que o objetivo da sua obra era o de descrever as salitreiras e os métodos de refino do nitrato de potássio visando seu melhor aproveitamento, substituindo a ignorância e os erros perpetuados pela empiria (denominados pelo autor de "vício da ignorância") por uma prática "esclarecida", baseada nas "luzes da ciência":

Os povos pasmaram quando, pela primeira vez, foram instruídos sobre aquelas mesmas coisas que tinham entre mãos, e se julgavam grandes sabedores em as manear (vício da ignorância); conheceram, afinal, seus desvios e pouco saber a esse respeito, e se aperfeiçoaram; pasmaram quando conheceram que suas terras eram suscetíveis de produzir muitos outros ricos gêneros, até então desconhecidos. (...) Esta preciosa região de Minas, criada ao desamparo, não produzia mais que ouro e diamantes, e os mineiros, na sua profissão, eram tão curtos como os agricultores; eles foram também, por sua vez, iluminados. E o seio da terra se descobriu às suas avaras vistas. ${ }^{2}$

\footnotetext{
1 COUTO, José Vieira. Memória sobre as salitreiras naturais de Monte Rorigo; maneira de as auxiliar por meio das artificiais; refinaria do nitrato de potássio ou salitre. Rio de Janeiro: na Impressão Régia, 1809, sem paginação.

2 COUTO, José Vieira. op. cit., 1809, sem paginação.
} 
rev. hist. (São Paulo), n. 173, p. 253-276, jul.-dez., 2015 http://dx.doi.org/10.11606/issn.2316-9141.rh.2015.107386
Sérgio Hamilton da Silva Barra

A Impressão Régia do Rio de Janeiro e a criaç̃óo do Novo Império português na América

A Memória de Vieira Couto era aquilo que se pode denominar de um manual de história natural, que contava com todas as características que marcaram o desenvolvimento e a divulgação das Luzes no Império português. A inserção de um diálogo ficcional em uma publicação de caráter científico é apenas uma dessas características. Como ressalta Maria de Fátima Nunes ao estudar o periodismo científico em Portugal entre finais do século XVIII e início do XIX, nessas publicações, a vertente de divulgação da ciência aparecia sempre associada à vertente literária: "o terreno comum aos intelectuais cientistas deixou-se também seduzir por um imaginário literário, pelo exótico da viagem ou da descrição do espaço diferente e longínquo ou ainda pela ciência transformada em espetáculo descritivo e literário". 30 pensamento ilustrado português tinha como motivação principal a superação do sentimento manifestado por estadistas e letrados naturais do Reino e das colônias na segunda metade do século XVIII, de que o Império português encontrava-se em uma situação de decadência econômica e atraso cultural. Assim, a difusão das Luzes em território português deu origem a uma cultura científica alicerçada em um pragmatismo que, orientado por uma política de Estado, estimulava os estudos de finalidade prática, em detrimento dos estudos políticos e filosóficos, tendo como principal objetivo a regeneração econômica do Reino, condição fundamental para evitar a fragmentação do Império. ${ }^{4}$ Fruto dessa política de Estado foi o desenvolvimento do conhecimento de história natural, em particular da colônia portuguesa da América, com a finalidade de desenvolver um novo padrão de exploração colonial que auxiliasse na superação daquela situação, ${ }^{5}$ o que aponta para

\footnotetext{
"NUNES, Maria de Fátima. Imprensa periódica científica (1772-1852): leituras de "sciencia agrícola" em Portugal. Lisboa: Estar Editora, 2001, p. 7.

${ }^{4}$ Lorelai Kury chama a atenção para o fato de que o pragmatismo não era um atributo exclusivo das Luzes portuguesas, tendo a defesa da utilidade dos estudos da natureza se transformado em lugar comum durante o alto Iluminismo. KURY, Lorelai. Homens de ciência no Brasil: impérios coloniais e circulação de informações (1780-1810). História, Ciências, Saúde - Manguinhos, vol. 11 (suplemento 1), 2004, p. 110.

5 Como explica José Luís Cardoso, a moderna historiografia econômica tem interpretado o último quartel do século XVIII português como um período de expansão e crescimento, euforia ou, pelo menos, relativa prosperidade. Conjuntura que seria substituída, no início do século XIX, por um quadro de crise propiciada seja pela concorrência dos produtos industriais ingleses, que aniquilava as capacidades do mal apetrechado parque manufatureiro do Reino; seja pela abertura dos portos brasileiros que fazia desabar um dos maiores esteios da prosperidade comercial; seja pelas invasões francesas que determinavam uma situação de caos na produção e circulação. CARDOSO, José Luís. O pensamento econômico em Portugal nos finais do século XVIII 1780-1808. Lisboa: Estampa, 1989, p. 37.
} 
rev. hist. (São Paulo), n. 173, p. 253-276, jul.-dez., 2015 http://dx.doi.org/10.11606/issn.2316-9141.rh.2015.107386
Sérgio Hamilton da Silva Barra

A Impressão Régia do Rio de Janeiro e a criação do Novo Império português na América

a existência de uma articulação entre política e cultura, ou entre saber e poder, no pensamento ilustrado português. Com o objetivo de recuperar o poder e o prestígio de que a monarquia portuguesa gozara outrora, a ciência aparece como fonte de conhecimento e como forma de domínio.

Na continuação da conversa dos dois viajantes da sua Memória, Vieira Couto nos revela que o nome com o qual batizou as montanhas onde se localizavam as promissoras salitreiras fazia uma homenagem ao ex-secretário de Estado dos Negócios da Marinha e Domínios Ultramarinos (entre 1796 e 1801) e então presidente do Real Erário (de 1801 a 1803), d. Rodrigo de Souza Coutinho (1755-1812):

Um rei tivemos, João O Máximo havia nome (Deus o tenha em santa glória) e VI era do nome: teve um ministro por nome Rodrigo, fiel executor de seus venturosos e altos projetos. Este Ministro (...) lançou suas penetrantes vistas (e sempre ao aceno de seu Rei) sobre este largo Império do Brasil. Então, dominava uma grosseira e bárbara agricultura. (...) Enfim, este Ministro primeiro lançou os fundamentos da nossa pública prosperidade, e é de seu nome que vem o deste Monte. Não sei se de seus começos se chamara logo Rorigo para maior correnteza e suavidade da palavra, ou se o tempo que tudo gasta (pois há ora isso já muitos séculos) também lhe gastou uma letra. ${ }^{6}$

A homenagem se justificava por ter sido d. Rodrigo o principal incentivador de uma política de fomento da produção e exploração das colônias ultramarinas portuguesas. Em particular, da colônia portuguesa da América, denominada pelo "genérico nome" de Império do Brasil. Tal atitude era representativa da sua consciência da fragilidade do Reino e da sua dependência econômica em relação à sua principal colônia. ${ }^{7}$ Ressalta Nívia Pombo Cirne dos Santos que, desde quando ainda atuava como diplomata em Turim (cargo exercido entre 1778 e 1796), d. Rodrigo passou a ser uma espécie de coordenador das atividades científicas nas colônias, sendo um grande entusiasta das expedições científicas ao ultramar. ${ }^{8} \mathrm{O}$ recurso a essas expedições, também conhecidas pelo nome de "viagens filosóficas", era complementado

6 COUTO, José Vieira, op. cit., 1809, sem paginação.

7 Segundo Tereza Cristina Kirschner, entre 1796 e 1807, as reexportações dos produtos da colônia no comércio externo português representavam 64,4\% do conjunto das exportações, contra apenas 29\% dos produtos da metrópole. KIRSCHNER, Tereza Cristina. José da Silva Lisboa, visconde de Cairu: itinerários de um ilustrado luso-brasileiro. São Paulo / Belo Horizonte: Alameda / PUC-Minas, 2009, p. 96.

8 SANTOS, Nívia Pombo Cirne dos. Dom Rodrigo de Souza Coutinho: pensamento e ação político-administrativa no Império português (1778-1812). Dissertação de mestrado em História Social, Departamento de História, UFF, 2002, p. 131-161. 
rev. hist. (São Paulo), n. 173, p. 253-276, jul.-dez., 2015 http://dx.doi.org/10.11606/issn.2316-9141.rh.2015.107386
Sérgio Hamilton da Silva Barra

A Impressão Régia do Rio de Janeiro e a criaç̃ó do Novo Império português na América

pelo envio de produtos de história natural para compor os acervos do $\mathrm{Mu}-$ seu de História Natural e do Jardim Botânico da Ajuda, em Lisboa. Dessa forma, tornou-se prática comum o trânsito de caixotes com amostras da flora e da fauna americanas entre a colônia e o Reino. A Memória de José Vieira Couto, por exemplo, foi enviada para d. Rodrigo acompanhada de dois caixotes de nitrato de potássio colhidos nas salitreiras que a obra descreve: "Nesta presente conjuntura, envio pela repartição do ultramar dois caixões de nitrato de potassa que foram colhidos como de passagem, enquanto me demorava sobre o lugar, a fim de estudar a Natureza do mesmo Nitrato, que ali se acha em abundância".?

Após assumir o posto de ministro da Marinha e Ultramar, Souza Coutinho empregou o conhecimento de bacharéis naturais do Brasil e formados na Universidade de Coimbra a serviço do desenvolvimento científico e econômico do Império. Esses homens compunham aquilo que Kenneth Maxwell denominou de a "geração de 1790", uma verdadeira "força-tarefa", incumbida de fornecer informações práticas para a Coroa portuguesa. Além do próprio Vieira Couto, natural do Arraial do Tejuco na capitania de Minas Gerais, pode-se destacar os nomes de José Bonifácio de Andrada e Silva (17631838), Hipólito José da Costa (1774-1823) e José da Silva Lisboa (1756-1835).10

Em 1798, Sousa Coutinho apresentou ao Conselho de Ministros de Portugal a sua Memória sobre o melhoramento dos domínios de sua majestade na América, um verdadeiro programa de reformas para a administração do Império, em que se sobressai a consciência de que o reerguimento do Império português dependia não apenas da manutenção e exploração racional da sua principal colônia, mas principalmente do reforço da ideia da existência de uma comunidade de interesses entre as duas partes do Império português. Dessa forma, o desenvolvimento da metrópole passava a ser concebido conjunta e articuladamente ao da sua principal colônia. Revertendo a lógica do processo histórico de dominação colonial, d. Rodrigo utilizou-se de tais argumentos

\footnotetext{
9 COUTO, José Vieira, op. cit., 1809, sem paginação. A respeito da preparação e remessa dos produtos de história natural para o Reino, ver DOMINGUES, Ângela. Para um melhor conhecimento dos domínios coloniais: a constituição de redes de informação no Império português em finais dos Setecentos. História, Ciências, Saúde - Manguinhos, vol. VIII (suplemento), 2001, p. 823-838; BARRA, Sérgio Hamilton da Silva. Ilustração e memória: a Impressão Régia do Rio de Janeiro e o projeto do novo Império português. Tese de doutorado em História Social da Cultura, Departamento de História da PUC-Rio, 2012.

${ }^{10}$ MAXWELL, Kenneth. A geração de 1790 e a ideia do Império luso-brasileiro. In: Idem. Chocolates, piratas e outros malandros: ensaios tropicais. Rio de Janeiro: Paz e Terra, 1999, p. 190.
} 
rev. hist. (São Paulo), n. 173, p. 253-276, jul.-dez., 2015 http://dx.doi.org/10.11606/issn.2316-9141.rh.2015.107386
Sérgio Hamilton da Silva Barra

A Impressão Régia do Rio de Janeiro e a criação do Novo Império português na América

para construir a imagem de uma "união natural" existente entre os interesses coloniais e os metropolitanos, em que deveria prevalecer o sentimento de pertencimento à nação lusa. O projeto de reformas ilustradas do ministro naturalizava a ideia da interdependência e da reciprocidade nas relações entre a metrópole e suas conquistas e, assim fazendo, como chamam a atenção José Luís Cardoso e Alexandre Mendes Cunha, não rompia com o modelo mercantilista tradicional sobre o papel das colônias nos impérios europeus.1 ${ }^{11}$

Fazia parte da política reformista ilustrada de d. Rodrigo de Sousa Coutinho a fundação de uma tipografia que assumisse o papel de difusão do conhecimento sobre história natural que visava incentivar o emprego de novos produtos e técnicas agrícolas ilustrados, atuando a partir de um modelo ilustrado de conhecer e intervir na realidade, resumido na frase sem livros não há ilustração. A Oficina Calcográfica, Tipoplástica e Literária do Arco do Cego, fundada em 1799 pelo ministro, que a colocou sob a direção do botânico natural de Minas Gerais, frei José Mariano da Conceição Veloso (1742-1811), constituiu-se no seu grande projeto tipográfico e editorial. Entre as principais tarefas editoriais da tipografia do Arco do Cego incluíam-se a compilação dos textos, tradução de obras em língua estrangeira e discussões sobre os diversos ramos da história natural. ${ }^{12}$ Como afirma Nívia P. C. dos Santos: "Acreditavam que a leitura teria o poder de melhorar o futuro dos homens, procurando divulgar algo que ainda estava inacessível para a maioria deles".13 Dessa forma, o periodismo científico se apresentava, como ressalta Maria de Fátima Nunes, ao mesmo tempo, assim como as academias literárias e cientificas oitocentistas, como espaço de circulação das ideias da

\footnotetext{
${ }^{11}$ CARDOSO, José Luís \& CUNHA, Alexandre Mendes. Discurso econômico e política colonial no Império luso-brasileiro (1750-1808). Revista Tempo. Niterói, vol. 17, nº 31, 2011, p. 83. Não é o caso de entrarmos aqui no debate historiográfico sobre a interpretação do momento do absolutismo ilustrado antes como continuidade do que como uma nova orientação política. Como explicam José Luís Cardoso e Alexandre Mendes Cunha, essa linha de interpretação insiste nos aspectos repressivos dessa modalidade do absolutismo como uma incongruência com o que seria esperado de um espaço político inspirado pelas Luzes. Esse aparente paradoxo também foi abordado por Kenneth Maxwell, ao comentar as reformas protagonizadas pelo marquês de Pombal que, apesar de inspiradas nas Luzes do século e tendentes a fecundar a modernização da monarquia portuguesa, tinham a finalidade última de reforçar os próprios fundamentos do Estado absolutista. (MAXWELL, Kenneth. Marquês de Pombal: O paradoxo do Iluminismo. Rio de Janeiro: Paz e Terra, 1996).

${ }^{12}$ Anteriormente, frei Veloso já havia sido editor do periódico agrário Paladio Portuguez ou Clarim de Pallas que anuncia os novos descobrimentos n'agricultura, artes, manufacturas, commercio etc., publicado pela Officina Patriarchal de Lisboa, entre abril e maio de 1796. NUNES, Maria de Fátima, op. cit., 2001, p. 67/68.

13 SANTOS, Nívia Pombo Cirne dos, op. cit., 2002, p. 220.
} 
rev. hist. (São Paulo), n. 173, p. 253-276, jul.-dez., 2015 http://dx.doi.org/10.11606/issn.2316-9141.rh.2015.107386
Sérgio Hamilton da Silva Barra

A Impressão Régia do Rio de Janeiro e a criaç̃ó do Novo Império português na América

Ilustração e espaço de sociabilidade dos letrados ligados ao campo das ciências naturais e físicas. ${ }^{14}$

A tipografia do Arco do Cego foi extinta pelo decreto de d. Rodrigo, de 7 de dezembro de 1801, que também reorganizou a Impressão Régia de Lisboa (criada pelo alvará de 24 de dezembro de 1768), transferindo para essa instituição o pessoal e oficinas da tipografia do Arco do Cego. Significativamente, d. Rodrigo extinguia o trabalho da tipografia do Arco do Cego no mesmo ano em que deixava a Secretaria de Estado da Marinha e Domínios Ultramarinos para assumir a Presidência do Erário Régio, ao qual a Impressão Régia de Lisboa estava subordinada. Dessa forma, transferia as funções de difusão de conhecimentos científicos sob o Império português para outra tipografia que continuaria sob o seu comando. Assim sendo, pode-se afirmar, como faz Nívia Pombo Cirne dos Santos, que esse trabalho de impressão e divulgação se encontrava no centro das preocupações de d. Rodrigo e de seu projeto de reformas ilustradas para o Império. ${ }^{15}$

Criada pelo decreto de 13 de maio de 1808 para dar continuidade na nova sede do Império português ao trabalho executado pela Impressão Régia de Lisboa, a tipografia do Rio de Janeiro manteve a função de difusora das Luzes no Império português. A presença em postos-chave da nova tipografia de letrados e estadistas que já haviam trabalhado e publicado nas tipografias então criadas para a divulgação das Luzes no Reino, resultou na continuidade do espírito pragmático que caracterizava a produção da ilustração portuguesa nas publicações da Impressão Régia do Rio de Janeiro. No entanto, a Impressão Régia do Rio de Janeiro surge em um momento no qual o projeto de reforma do Império se transforma em um projeto de constru-

\footnotetext{
${ }^{14}$ A autora chama a atenção para o papel das academias literárias na derrocada daquilo que ela denomina de uma forma mentis barroca e uma gradual e progressiva aproximação do mundo natural. NUNES, Maria de Fátima, op. cit., 2001, p. 34/35. Antes mesmo do empreendimento da tipografia do Arco do Cego, a criação da Academia Real das Ciências de Lisboa, no final de 1779, já havia aberto amplas possibilidades de reflexão e divulgação de memórias e projetos que expressavam a relação intrínseca existente entre o pensamento ilustrado português e a implementação de reformas políticas ilustradas. O resultado dessas reflexões está registrado nas Memórias econômicas para o adiantamento da agricultura, das artes e da indústria em Portugal e suas conquistas, publicadas pela Academia de Ciências, em cinco tomos, entre 1789 e 1815. Outras tipografias também colaboraram para a intensificação da circulação de impressos de natureza técnico-científica, tais como as de Procópio Correia da Silva, Simão Thadeu Ferreira, João Antonio da Silva e a de Antonio Rodrigues Galhardo, que editava, também a partir do ano de 1779, o Jornal Encyclopedico. Dedicado à rainha Nossa Senhora, destinado à instrução geral, com a notícia dos novos descobrimentos em todas as sciencias e artes. A respeito desse periódico, ver NUNES, Maria de Fátima, op. cit., 2001, p. 56-59.

15 SANTOS, Nívia Pombo Cirne dos, op. cit., 2002, p. 217 a 222.
} 
rev. hist. (São Paulo), n. 173, p. 253-276, jul.-dez., 2015 http://dx.doi.org/10.11606/issn.2316-9141.rh.2015.107386
Sérgio Hamilton da Silva Barra

A Impressão Régia do Rio de Janeiro e a criação do Novo Império português na América

ção de um novo Império português na sua colônia da América. Dessa forma, a sua função cultural de difundir o conhecimento das Luzes na nova sede do Império português se apresentava ao mesmo tempo como uma função política, desempenhando importante papel de legitimação e sustentação de um projeto político posto em prática por d. João e d. Rodrigo de Sousa Coutinho a partir de novembro de 1807, quando os navios que levavam a corte portuguesa para longe das tropas napoleônicas zarparam do porto de Lisboa.

\section{Um projeto político como herança}

Em 1803, ao ser consultado sobre a situação europeia, d. Rodrigo de Sousa Coutinho apresentou ao Conselho de Estado a sua Memória sobre a mudança da sede da monarquia, em que afirmava que Portugal não era a melhor parte da monarquia e, em sua opinião, diante do quadro de incertezas que rondava o reino na Europa, sempre restaria ao soberano a alternativa de criar um poderoso império no Brasil, de onde poderia tornar a reconquistar o que tivesse perdido na Europa. A proposta de transferência da Corte para os domínios portugueses da América não era nova. Havia sido considerada por diversos estadistas e letrados portugueses desde a restauração da monarquia em 1640, mas ganhou força durante o século XVIII, no contexto do reformismo ilustrado. ${ }^{16}$ Dessa forma, ao finalmente ser posta em prática, em finais de 1807, a transferência da Corte não atendia somente a uma necessidade conjuntural imediata, mas efetivava o projeto reformista ilustrado de reerguimento do Império português a partir da sua mais próspera colônia. ${ }^{17}$

\footnotetext{
${ }^{16}$ No início do século XVIII, d. Luiz da Cunha, embaixador em Paris e delegado nas negociações do Tratado de Utrecht (1713-1715), já chamara a atenção para a preeminência do Estado do Brasil sobre todas as outras partes constituintes do Império português, incluindo a própria metrópole. Ele observou que enquanto o Brasil era virtualmente um continente, Portugal não passava de uma "orelha de terra". O cerne do pensamento de Cunha baseava-se na ideia de que não podia el-rei manter Portugal sem o Brasil, enquanto, para manter o Brasil, não carecia de Portugal. A solução proposta pelo estadista era mudar a corte para o Brasil, onde d. João $\mathrm{V}$ poderia tomar o título de "emperador do Ocidente". SCHULTZ, Kirsten. Versalhes tropical: Império, monarquia e a corte real portuguesa no Rio de Janeiro, 1808-1821. Rio de Janeiro: Civilização Brasileira, 2008, p. 42 a 44.

${ }^{17}$ Esse projeto político de criação de um novo Império português nos trópicos ficou expresso no manifesto publicado a $1^{\circ}$ de maio de 1808 , em que d. João, recém-instalado no Rio de Janeiro, afirmava que não era com injúrias e nem com vãs ameaças que "a Corte de Portugal levantará a sua voz do seio do novo império que vai criar". Manifesto ou exposição fundada, e justificativa do procedimento da Corte de Portugal a respeito da França, desde o princípio da Revolução até a época da invasão de Portugal e dos motivos que a obrigaram a declarar a guerra ao imperador dos franceses, pelo fato da invasão e da subsequente declaração de guerra feita
} 
Porém, a execução desse projeto não podia ocorrer sem provocar uma profunda modificação em relação ao que havia sido pensado nos planos do reformismo ilustrado português. Na nova situação criada pela transferência, o antigo Reino perdia o papel de nexo da unidade imperial, de centro do Império que mantinha no programa de reformas de d. Rodrigo de Sousa Coutinho, e colocava em segundo plano os interesses da burguesia mercantil e manufatureira do Reino e dos membros da nobreza que não tinham interesses no Brasil. O "apoio das Luzes ao trono", expressão utilizada por José da Silva Lisboa para se referir à "política de promoção das ciências e das artes" praticada por d. João, ${ }^{18}$ era mais do que benvindo nessa conjuntura delicada da história da monarquia portuguesa, que colocava o príncipe regente na posição de ver como única salvação para a sua Coroa o abandono da metrópole e a instalação em território colonial. Frente a todos os problemas de legitimidade que essa situação gerava, a Impressão Régia do Rio de Janeiro desempenhou o importante papel político de sustentação da monarquia. Assim, na esteira das reflexões de Ilmar R. de Mattos, podemos afirmar que a criação do novo Império português não seria feita a partir do nada, mas sobre uma herança. E a herança que definia os marcos dessa construção era o patrimônio intelectual do reformismo ilustrado português. Mas, ao mesmo tempo, o autor chama a atenção para o fato de que a própria herança pode ser entendida como uma construção. ${ }^{19}$

A criação da Impressão Régia do Rio de Janeiro fez parte do processo de instalação do aparelho burocrático do Império português no Rio de Janeiro. Atentando para a determinação, inclusa no seu decreto de criação, de que a nova tipografia deveria ficar subordinada à Secretaria dos Negócios Estrangeiros e da Guerra, então sob a responsabilidade de d. Rodrigo de Sousa Coutinho, o principal artífice da construção do novo Império, podemos vislumbrar o importante papel político que lhe era reservado dentro da estrutura administrativa do Estado português. Cabia ao novo órgão a impressão de toda a legislação e papéis diplomáticos que emanassem de qualquer repartição do real serviço. E, como não havia outra tipografia na colônia,

em consequência do relatório do ministro das Relações Exteriores. COSTA, Hipólito José da. Correio Braziliense ou Armazém Literário, setembro de 1808, p. 256.

${ }^{18}$ LISBOA, José da Silva. Memória dos benefícios políticos do governo de el-rey nosso senhor d. João VI. Rio de Janeiro: na Impressão Régia, 1818, p. 21. A paginação aqui utilizada se refere à edição facsimilar publicada pelo Arquivo Nacional em 1940.

${ }^{19}$ MATTOS, Ilmar Rohloff de. Construtores e herdeiros: a trama dos interesses na construção da unidade política. Almanack Brasiliense. São Paulo: USP, nº 1, maio de 2005, p. 23. 
ao menos oficialmente, cabia-lhe também imprimir todas as outras obras, porém, apenas depois de cumprida a tarefa de publicar os atos do governo, necessária e essencial ao bom andamento da burocracia. ${ }^{20}$

Em junho de 1808, foi nomeada uma junta administrativa para a Impressão Régia, composta de três membros, que tinha entre as suas atribuições o exame de tudo o que se mandasse publicar e o impedimento da impressão de papéis e livros cujo conteúdo contrariasse o governo, a religião e os bons costumes. Por meio do decreto de 27 de setembro de 1808, o príncipe regente atendeu à solicitação da Mesa do Desembargo do Paço que reivindicava o seu direito de exercer a jurisdição sobre a censura de livros, com base no alvará de 17 de dezembro de $1794 .{ }^{21}$ Esse aparato censório vigorou durante praticamente todo o período de governo de d. João no Rio de Janeiro. Até que, em 2 de março de 1821, d. João foi obrigado a assinar, por pressão da Junta de Governo da Revolução do Porto, um decreto que abolia a censura prévia para a imprensa em geral. Após a regulamentação da liberdade de imprensa nos debates constitucionais nas Cortes de Lisboa e o aviso do príncipe regente d. Pedro de 28 de agosto de 1821, que estabelecia a efetiva abolição da censura prévia no Brasil, embora com restrições, multiplicaram-se as tipografias particulares. A partir desse momento, não se pode mais aludir ao papel político da Impressão Régia na legitimação e sustentação da monarquia, uma vez que, não estando mais submetida à censura oficial, a tipografia muda de caráter, participando intensamente do debate sobre a monarquia constitucional. Além disso, a pluralidade de vozes abafaria a sua eficácia no desempenho daquele papel.

Maria Odila da Silva Dias chama a atenção para a filiação entre a Impressão Régia do Rio de Janeiro e suas antecessoras reinóis, ao comentar as atividades de d. Rodrigo de Sousa Coutinho no Brasil. Segundo a autora, o estadista retomou, na Impressão Régia do Rio de Janeiro, "a publicação de trabalhos por ele encomendados de 1798 a 1803, patrocinando novos estu-

${ }^{20}$ MORAES, Rubens Borba de. Livros e bibliotecas no Brasil colonial. São Paulo: Secretaria de Cultura, Ciência e Tecnologia, 1979, p. 99 a 101. Entre 1808 e 1822, a Impressão Régia do Rio de Janeiro publicou mais de mil itens, entre folhetos, opúsculos, sermões, oratória sacra, odes, prospectos, peças de teatro, obras literárias e científicas versando sobre agricultura, comércio, ciências naturais, matemática, história, economia política, direito, medicina, filosofia, romance, poesia e educação, além de traduções de textos franceses e ingleses.

${ }^{21}$ O alvará de 17 de dezembro de 1794 extinguiu a Comissão Geral para o Exame e a Censura dos Livros criada por decreto de d. Maria I, de 21 de junho de 1787, reestabelecendo a censura tripartida exercida pelo Ordinário, pela Inquisição e pelo Desembargo do Paço. 
rev. hist. (São Paulo), n. 173, p. 253-276, jul.-dez., 2015 http://dx.doi.org/10.11606/issn.2316-9141.rh.2015.107386
Sérgio Hamilton da Silva Barra

A Impressão Régia do Rio de Janeiro e a criaç̃óo do Novo Império português na América

dos, de orientação prática, para servirem ao progresso das artes, técnicas, da lavoura e da pecuária".22 O melhor exemplo dessa filiação talvez seja a publicação pela Impressão Régia, entre janeiro de 1813 e dezembro de 1814, da revista $O$ Patriota: Jornal literário, político e mercantil. Primeiro periódico dedicado à cultura e às ciências produzido na colônia, publicava estudos de literatura, história, geografia, estatística, política, filosofia entre outros temas. Segundo Lorelai Kury, a diversidade temática dos artigos de $O$ Patriota, fruto do "caráter enciclopédico" do trabalho dos seus colaboradores, e a preocupação didática na forma da abordagem, ligam o periódico ao ambiente intelectual ilustrado europeu. ${ }^{23}$ O Patriota pode ser considerado herdeiro do periodismo científico reinol de finais dos Setecentos e inícios dos Oitocentos, apresentando a mesma preocupação com a aplicação prática das disciplinas abordadas que caracterizavam as memórias publicadas no ambiente ilustrado português. Com relação às memórias sobre os diferentes ramos da história natural, são trabalhos essencialmente técnicos, que abordam as minúcias do modo de produção dessas culturas, visando otimizar o seu aproveitamento econômico, corrigindo os erros perpetuados por uma prática baseada exclusivamente na empiria. Como chama a atenção Lorelai Kury, "a ciência que se quer patriótica é indissociável de seus desdobramentos úteis". ${ }^{24}$ Assim sendo, afirma a autora que o periódico pretendia, assim como as publicações do Arco do Cego, formar leitores, escritores e também agricultores:

O Patriota pretendeu influenciar a própria formação dos homens de letras locais, tanto na qualidade de leitores quanto na de escritores. Seu didatismo é também manifesto em sua maneira de fundar uma síntese do que era sabido sobre as terras brasileiras. (...) Assim, é nessa confluência entre a construção de uma singularidade brasileira, inserida

\footnotetext{
${ }^{22}$ DIAS, Maria Odila da Silva. Aspectos da Ilustração no Brasil. Revista do Instituto Histórico e Geográfico Brasileiro. Rio de Janeiro: IHGB, vol. 278, jan./mar. 1968, p. 126. Maria de Fátima Nunes chama a atenção para a permanente presença dos temas agrários no periodismo científico português entre o último quartel do século XVIII e a primeira metade do século XIX. Ou, como afirma a autora, na passagem do Iluminismo para o Liberalismo. Essa permanência estaria relacionada ao fato de que, na primeira metade dos Oitocentos, a sociedade e a economia portuguesa ainda seriam muito dependentes da atividade agrícola. NUNES, Maria de Fátima, op. cit., 2001.

${ }^{23}$ KURY, Lorelai. Descrever a pátria, difundir o saber. In: KURY, Lorelai (org.). Iluminismo e Império no Brasil: O Patriota (1813-1814). Rio de Janeiro: Editora Fiocruz, 2007, p. 141.

${ }^{24}$ KURY, Lorelai, op. cit., 2007, p. 142.
} 
no universo imperial português, e os modelos científicos dos centros europeus que se constitui uma das principais manifestações do iluminismo luso-americano. ${ }^{25}$

Essa relação fica ainda mais clara se atentamos para o fato de que não é difícil encontrar nas páginas do periódico obras escritas no final do século XVIII, algumas já publicadas antes pela tipografia do Arco do Cego. É o caso da Memória sobre a canela do Rio de Janeiro, de Bernardino Antonio Gomes, publicada no Rio de Janeiro em 1809. Na folha de rosto, há a informação de que ela foi escrita "a rogo do Senado da Câmara" do Rio de Janeiro, na data de 8 de maio de 1798. Na sua Memória, Gomes aponta as falhas decorrentes de um cultivo não ilustrado e a má utilização do potencial econômico da caneleira no Rio de Janeiro, apesar do clima e do solo dessa capitania não ser o ideal para essa cultura:

Neste ditoso país onde, bem como por toda a parte, é a negligência dos habitantes na razão direta da liberalidade da natureza, apenas as folhas desta árvore eram de algum uso. Preparavam com elas uma água aromática de que se não serviam mesmo senão para jogar o entrudo. Tão pouca era a utilidade que tiravam desta árvore que, independentemente da canela, porque aliás é cultivada e tão célebre, é muito preciosa ainda por outros títulos. ${ }^{26}$

Outro exemplo seria a Memória sobre a cultura dos algodoeiros e sobre o método de o escolher e ensacar, de Manuel Arruda da Câmara (1752-1811), escrita em 1797 e publicada pela tipografia do Arco do Cego dois anos depois. Foi reeditada em $O$ Patriota em 1813. Seguindo o espírito ilustrado das demais memórias publicadas pelo Arco do Cego, o trabalho de Arruda da Câmara procurava "iluminar" os produtores de algodão, desfazendo alguns erros perpetuados por uma prática "não científica" daquela cultura. Dessa forma, ao discorrer sobre a melhor maneira de plantar os algodoeiros, Câmara propõe um método novo, em oposição ao comumente utilizado pelos agricultores, alertando para a ignorância de não adotá-lo: "Há agricultores que (...) refusam este método de plantar. Porém, estes são do número daqueles que, por evitarem

\footnotetext{
${ }^{25}$ KURY, Lorelai, op. cit., 2007, p. 142.

${ }^{26}$ GOMES, Bernardino Antonio. A. Memória sobre a canela do Rio de Janeiro, oferecida ao príncipe do Brasil nosso senhor pelo Senado da Câmara da mesma cidade do ano de 1798. Rio de Janeiro: na Impressão Régia, 1809, p. 39/40.
} 
rev. hist. (São Paulo), n. 173, p. 253-276, jul.-dez., 2015 http://dx.doi.org/10.11606/issn.2316-9141.rh.2015.107386
Sérgio Hamilton da Silva Barra

A Impressão Régia do Rio de Janeiro e a criaç̃óo do Novo Império português na América

um pequeno incômodo presente, se privam de tantos bens futuros. Funestos efeitos da preguiça, maior causa da pobreza e do descômodo da vida". ${ }^{27}$

A Impressão Régia publicou também o primeiro periódico da colônia: a Gazeta do Rio de Janeiro, responsável pela divulgação dos atos do monarca, do calendário ritual da Corte e de notícias de cunho político tiradas de periódicos europeus, sobretudo ingleses e franceses. Ainda que não fosse um periódico destinado exclusivamente à divulgação científica, também desempenhou esse papel ao dar notícia da produção de obras, textos, cursos e publicar, ocasionalmente, memórias técnicas com algum conteúdo científico. Em abril de 1812, por exemplo, o periódico publicou uma grande matéria sobre o anil, dividida em quatro partes. ${ }^{28}$ A matéria, intitulada Noções sobre o anil, segue as mesmas características pragmáticas do memorialismo científico ilustrado português, apresentando a descrição e classificação científica da planta, suas formas de cultivo, de fabricação da tinta, análise da composição química da tinta e, principalmente, a importância econômica e estado atual do comércio do anil no Império português. A respeito desse último ponto, escreve o autor:

O distrito em que tem caído na Europa o anil do Brasil, o qual, tendo todas as razões para formar um avultado ramo do comércio de exportação neste país, se acha reduzido a um sumo estado de decadência pela negligência com que até agora tem sido fabricado, que lhe tem alcançado o último lugar nos preços correntes estrangeiros, nos obriga a transcrever aqui a benefício do comércio as seguintes observações, que são necessárias para se conhecer no trato mercantil a qualidade do anil, a fim de que nossos comerciantes, acostumando-se a não exportar senão o bom anil, possam restituir a reputação a esta preciosa parte de nossas riquezas nacionais. ${ }^{29}$

Juliana Gesuelli Meirelles e Lilia Moritz Schwarcz chamam a atenção para o papel de relevo desempenhado pela Gazeta do Rio de Janeiro na sustentação do reinado de d. João no Rio de Janeiro. Referindo-se à ligação do periódico com a Secretaria dos Negócios Estrangeiros e da Guerra, afirma Schwarcz que "com essa origem, a Gazeta do Rio de Janeiro seria o veículo certo para publicar feitos da monarquia que contribuíssem para expandir a ima-

\footnotetext{
${ }^{27}$ CÂMARA, Manuel Arruda da. Memória sobre a cultura dos algodoeiros e sobre o método de o escolher e ensacar. O Patriota: Jornal literário, político e mercantil. Rio de Janeiro: na Impressão Régia, $\mathrm{n}^{\mathrm{0}} 3$, março de 1813, p. 47.

${ }^{28}$ Gazeta do Rio de Janeiro, ${ }^{\circ}$ 29, de 8 de abril; $n^{\circ}$ 30, de 11 de abril; $n^{\circ}$ 31, de 15 de abril e ${ }^{0}$ 32, de 18 de abril de 1812.

${ }^{29}$ Gazeta do Rio de Janeiro, ${ }^{\circ}$ 32, 18 de abril de 1812.
} 
gem que lhe convinha" ${ }^{30}$ Enquanto Meirelles explica que fosse incentivando financeiramente as folhas de interesse real, fosse combatendo os jornais de tendência ofensiva ao governo, a Coroa portuguesa sob o governo joanino concebeu a imprensa como "parte fundamental da sua ação política e cultural e, consequentemente, em um âmbito mais amplo, como âncora de sustentação do Império português em ambos os lados do Atlântico". ${ }^{31}$

Ao lado da história natural, a economia política era considerada pelos letrados portugueses uma das ciências capazes de tirar o Império da situação de crise econômica e atraso cultural em que se encontrava. Segundo Antonio Penalves Rocha, a difusão dessa ciência entre os letrados luso-brasileiros, entre fins do século XVIII e inícios do XIX, ocorreu sob forte entusiasmo. Tratava-se de um conhecimento que tinha em vista proporcionar o enriquecimento nacional a partir da investigação das "leis naturais" que regulam a produção, a distribuição e a acumulação das riquezas, e da sua transformação em preceitos práticos que podiam "prover as necessidades e comodidades da nação". ${ }^{2}$ Dessa forma, a economia política caracterizava-se como uma ciência pragmática, cujo principal objetivo era promover a riqueza e o desenvolvimento da nação, bem de acordo com a orientação do reformismo ilustrado português do final do século XVIII. Dois autores se destacaram por proporem encaminhamentos diferentes e, em muitas medidas, antagônicos para a superação dessa situação de crise: José da Silva Lisboa e José Acúrsio das Neves.

Obras como as Observações sobre o comércio franco do Brasil (1808), as Observações sobre a franqueza da indústria e estabelecimento de fábricas no Brasil (1810) ou as Observações sobre a prosperidade do Estado pelos liberais princípios da nova legislação do Brasil (1810), todas de autoria de José da Silva Lisboa, tinham prioridade de impressão na nova tipografia. Ele pode ser considerado um dos construtores do novo Império português, uma vez que ocupou importantes posições na administração durante o reinado de d. João, tendo sido membro da Junta Administrativa da Impressão Régia e desembargador do Desembargo do Paço, o que lhe valia o cargo de censor régio. Não por acaso, o letrado bahiense foi também o autor que mais obras publicou pela Impressão Régia do Rio de Janeiro. Admirador de Adam Smith, ele "estava convencido de que as teorias

\footnotetext{
${ }^{30}$ SCHWARCZ, Lilia Moritz. A longa viagem da biblioteca dos reis: do terremoto de Lisboa à Independência do Brasil. São Paulo: Companhia das Letras, 2002, p. 252.

${ }^{31}$ MEIRELLES, Juliana Gesuelli. Imprensa e poder na corte joanina: A Gazeta do Rio de Janeiro (1808-1821). Rio de Janeiro: Arquivo Nacional, 2008, p. 141.

${ }^{32}$ ROCHA, Antônio Penalves. A economia política na sociedade escravista: um estudo dos textos econômicos de Cairu. São Paulo: Hucitec, 1996.
} 
rev. hist. (São Paulo), n. 173, p. 253-276, jul.-dez., 2015 http://dx.doi.org/10.11606/issn.2316-9141.rh.2015.107386
Sérgio Hamilton da Silva Barra

A Impressão Régia do Rio de Janeiro e a criaç̃óo do Novo Império português na América

do economista inglês fariam a prosperidade do Brasil", como afirma Rubens Borba de Moraes..$^{33}$ Dessa forma, a sua principal preocupação nas suas obras de economia política foi defender e legitimar a instituição da liberdade de comércio pela Carta Régia de abertura dos portos, de 28 de janeiro de 1808, o que está expresso na justificativa das suas Observações sobre o comércio franco no Brasil:

\begin{abstract}
Senhor, devendo ser o voto de quaisquer fiéis vassalos que o nome de V. A. R. seja celebrado em todas as nações; e sendo o meu principal empenho que a humanidade consagre a V. A. R. o título de Libertador do Comércio; (...) considerei que seria de algum serviço ao Estado o fazer apreciar em público a incomparável mercê que V. A. R. se dignou conferir a estes seus domínios ultramarinos, permitindo a franqueza do comércio; sendo este imenso benefício o precursor de muitos outros, com que se liberaliza continuamente o bem geral. (...) pois estou convencido que a franqueza do comércio, regulada pela moral retidão, e bem comum, é o princípio vivificante da ordem social, e o mais natural, e seguro meio da prosperidade das nações. ${ }^{34}$
\end{abstract}

Rubens Borba de Moraes chama a atenção para o oportunismo da publicação de obras que propagandeassem e elogiassem a franqueza do comércio e, consequentemente, a nova política econômica da monarquia portuguesa naquele momento: "Um livro como o de Silva Lisboa, defendendo o comércio livre e provando, baseado nas teorias de Adam Smith, que o 'commercio franco' traria prosperidade para todos não podia deixar de merecer impressão rápida e prioritária". ${ }^{35} \mathrm{~A}$ tarefa principal a que se dedicou Silva Lisboa nas suas obras sobre economia política foi a de rebater as críticas à política econômica do príncipe regente, da qual ele se considerava um dos idealizadores:

Não dissimulo que as vantagens do comércio franco têm sido controvertidas por escritores de nota; e que as circunstâncias de cada país podem justificar algumas restrições, temporárias, ou permanentes, do tráfico estrangeiro, compensando-se, por cálculo prudente, com o bem geral. Assim protesto, que em nada intento deprimir o patriotismo, e mérito dos que discordam de mim em tal assunto. Respeito o juízo de todos; não presumo que o meu seja a medida da verdade, só desejo que prevaleça o que for realmente o mais útil ao Estado. ${ }^{36}$

\footnotetext{
33 MORAES, Rubens Borba de, op. cit., 1979, p. 114.

${ }^{34}$ LISBOA, José da Silva. Observações sobre o comércio franco no Brasil. In: ROCHA, Antônio Penalves (org.). José da Silva Lisboa: visconde de Cairu. São Paulo: Editora 34, 2001, p. 63/64.

35 MORAES, Rubens Borba de, op. cit., 1979, p. 103.

${ }^{36}$ LISBOA, José da Silva, op. cit., 2001, p. 65/66.
} 
Para Silva Lisboa, o alvará de Abertura dos Portos indicava o início de uma era promissora para o Brasil. O livre comércio, além de beneficiar a classe mercantil sediada na colônia e, consequentemente, a Coroa (pelo aumento de arrecadação), promoveria também a conciliação dos interesses dos diferentes setores sociais do Império. Ele tentava mostrar aos comerciantes monopolistas que, depois de 1808, não haveria redução dos lucros devido às suas transações comerciais com o restante da Europa e à tradição dos negócios portugueses no Brasil. A plena liberdade para comprar e vender garantia, em qualquer circunstância, que ambas as partes envolvidas na relação de troca seriam beneficiadas. Dessa forma, o pensamento de Silva Lisboa prometia também à classe dirigente do Império que a liberdade de comércio atenuaria as tensões sociais, pela sua capacidade de promover o desenvolvimento econômico:

O verdadeiro interesse do soberano é que as colônias sejam cordialmente unidas a seu governo e pátria comum, e que prosperem o mais possível; pois, de sua íntima união e constante prosperidade depende a maior possível renda e força do Estado. A franqueza do comércio não tende a sacrificar a metrópole aos domínios ultramarinos; mas fazer crescer todas as partes integrantes da monarquia pelos seus naturais meios de crescimento, e não à custa das outras. ${ }^{37}$

Em outra obra, em que ressalta que o fim da economia politica era promover o "bem comum", Silva Lisboa prometia também à classe dirigente do Império que a liberdade de comércio, pela sua capacidade de promover o desenvolvimento econômico, atenuaria as tensões sociais. A sociedade colonial era marcada por uma desigualdade social acentuada, sobre a qual pesava a ameaça de revolução feita pelos destituídos da propriedade, reforçada pelos acontecimentos do Haiti. Segundo o seu raciocínio, a incapacidade para favorecer o "bem comum" demonstrava a artificialidade do sistema colonial e a sua ingovernabilidade. O livre comércio afastaria a hipótese de tal revolução porque superaria a ordem colonial e a ultrapassaria em favor de uma "ordem civil melhorada, refinada, plena de civilidade". Dessa forma, através da prática do livre comércio estaria assegurada a riqueza nacional e, consequentemente, a ordem social:

A economia política, inquirindo os regulares meios do inocente e natural progresso da opulência, demonstrando as péssimas consequências dos odiosos monopólios, con-

${ }^{37}$ LISBOA, José da Silva, op. cit., 2001, p. 155. 
rev. hist. (São Paulo), n. 173, p. 253-276, jul.-dez., 2015 http://dx.doi.org/10.11606/issn.2316-9141.rh.2015.107386
Sérgio Hamilton da Silva Barra

A Impressão Régia do Rio de Janeiro e a criaç̃óo do Novo Império português na América

vencendo o fatal erro de se ter o ouro e a prata como a riqueza essencial das nações, expondo os meios de todos os povos se enriquecerem e prosperarem pelo comércio legítimo, sem que o benefício de uns se converta em malefício dos outros, contribui a exterminar a excessiva desigualdade dos indivíduos e as causas das guerras, e a dar a todas as classes e nações harmonia e prosperidade. ${ }^{38}$

Segundo Antonio Penalves Rocha, a importância da obra econômica de Silva Lisboa residiria justamente na destinação que ele deu à economia política, utilizando seu vocabulário e seu aparato conceitual para defender e legitimar as mudanças em curso no Império português depois da transferência da Corte para a América. ${ }^{39}$ Ressalta o autor que o nexo entre economia política e poder do Estado no Império português do início do século XIX somente se torna inteligível se levarmos em consideração o quadro de desestabilização provocado pelo estabelecimento da sede da monarquia no Rio de Janeiro. A necessidade de estabelecer as bases políticas de sustentação do novo Estado levou a monarquia a privilegiar os interesses dos grupos influentes da sociedade colonial (grandes proprietários e comerciantes abastados, principalmente do Centro-Sul), pelo atendimento de suas demandas. A política econômica levada a cabo a partir de então desagradou outros grupos, principalmente a burguesia mercantil e manufatureira do Reino, paulatinamente preterida em seus direitos e reivindicações. Esses setores sociais sentiam-se lesados e se opunham à nova política econômica do príncipe regente, contestando a legitimidade do seu governo do Império. Como afirma Rocha, para que o equilíbrio fosse reconstituído havia a necessidade, antes de tudo, de legitimar as medidas tomadas pela monarquia no Brasil:

A legitimação seria o primeiro passo para um possível reajustamento do Império português às mudanças que decorreram da transferência da sede da monarquia para o Brasil. E é no plano ideológico desse quadro histórico, principalmente a serviço dessa legitimação que a economia política de Silva Lisboa assumiu uma importância considerável; não era, portanto, por motivos gratuitos que seus textos batiam insistentemente na tecla da harmonia de interesses, que resultaria do livre comércio. (...) O discurso econômico colaborava, portanto, para a reacomodação do Estado português às novas

\footnotetext{
${ }^{38}$ LISBOA, José da Silva. Estudos do bem comum e economia política ou ciência das leis naturais e civis de animar e dirigir a geral indústria e promover a riqueza nacional e prosperidade do Estado. Rio de Janeiro: IPEA/INPES, 1975, p. 156.

39 ROCHA, Antônio Penalves (org.), op. cit., 2001, p. 36.
} 
circunstâncias, fornecendo às partes que o compunham a perspectiva de alcançarem uma ordem natural, que teria como signos a abundância e a felicidade. ${ }^{40}$

Ao mesmo tempo em que José da Silva Lisboa publicava os seus estudos de economia política no Rio de Janeiro, um homônimo seu também escrevia os seus na antiga capital do Império: José Acúrsio das Neves. Bacharel em Direito pela Universidade de Coimbra (1787), desembargador do Desembargo do Paço, sócio da Academia Real das Ciências de Lisboa, desembargador da Relação do Porto, deputado e secretário da Real Junta do Comércio, Agricultura, Fábricas e Navegação, Acúrsio das Neves escrevia a partir de sua posição de dentro da administração do Estado português, assim como Silva Lisboa no Rio de Janeiro, o que certamente lhe garantia uma maior facilidade para a publicação de suas obras no Reino, mas não na nova Corte. As memórias econômicas de Acúrsio das Neves nunca foram reeditadas pela Impressão Régia do Rio de Janeiro.

É na sua Memória sobre os meios de melhorar a indústria portuguesa, considerada nos seus diferentes ramos (1820) que pode ser identificado o princípio que fundamenta o seu pensamento econômico: a necessidade do desenvolvimento conjunto dos três setores econômicos que são interpretados por Acúrsio como ramos da indústria (a agricultura, as manufaturas e o comércio). Nessa obra, Acúrsio confirma esse diagnóstico de uma situação de profunda crise econômica no Reino:

Não se pode duvidar da existência dos nossos males, porque os sentimos, e gravíssimos, pois atacam na sua origem as principais fontes da prosperidade pública. Males desta natureza não se curam senão com remédios radicais, e para estes se descobrirem e aplicarem é necessário conhecer a doença nacional; portanto, o primeiro passo deve ser a investigação das causas que nos conduziram à presente crise, procedendo com aquela decente liberdade que permitem os Governos justos, mas não insistindo no passado, senão em quanto for necessário para regular o futuro. ${ }^{41}$

Na investigação das causas que estavam na origem da situação de crise da economia do reino, o autor identifica, em primeiro lugar, as invasões francesas e, principalmente, o seu mais funesto efeito, a transferência da sede da monarquia para a América. A abertura dos portos da América por-

\footnotetext{
${ }^{40}$ ROCHA, Antonio Penalves, op cit., 1996, p. 117.

${ }^{41}$ NEVES, José Acúrsio das. Memória sobre os meios de melhorar a indústria portuguesa, considerada nos seus diferentes ramos. Lisboa: Impressão Régia, 1820, p. 75/76.
} 
rev. hist. (São Paulo), n. 173, p. 253-276, jul.-dez., 2015 http://dx.doi.org/10.11606/issn.2316-9141.rh.2015.107386
Sérgio Hamilton da Silva Barra

A Impressão Régia do Rio de Janeiro e a criaç̃óo do Novo Império português na América

tuguesa e a consequente perda por Portugal do papel de intermediário do comércio colonial, resultado desse processo, foi para Acúrsio o golpe de misericórdia na economia do Reino, já debilitada pelas três invasões francesas:

Foi o resultado de todas estas causas, que perdido o mercado exclusivo das produções da nossa indústria, que era principalmente no Brasil, e não podendo elas sustentar mesmo em Portugal a concorrência das manufaturas estrangeiras, vimos quase aniquiladas as nossas fábricas, depois de arruinada a nossa agricultura nas terras invadidas, sem ao menos passarmos por algum intervalo que nos preparasse para tão grandes mudanças. ${ }^{42}$

Diante desse quadro, o desenvolvimento da indústria no Reino, pelo fomento conjunto dos seus três ramos, aparecia para Acúrsio como única saída para a crise. E para viabilizar esse desenvolvimento, ele considerava como medida indispensável a manutenção do vínculo político pela intensificação das relações mercantis entre o Reino e as possessões ultramarinas, em particular com o Brasil. Mas ele reconhecia a inviabilidade do retorno ao regime de exclusivo comercial anterior a 1808. Na impossibilidade de reestabelecer o antigo pacto colonial, Acúrsio propõe a manutenção de Portugal como principal parceiro comercial do Brasil, como não poderia deixar de ser, aliás, sendo os dois reinos pertencentes a uma mesma monarquia. Assim, dois princípios deveriam embasar a política econômica do Reino:

$1^{\circ}$ Chamar outra vez a Portugal, por meios indiretos e de conveniência para ambas as partes o comércio do Brasil; de forma que Portugal seja o principal entreposto dos gêneros coloniais. $2^{\circ}$ Dar preferência no Brasil ao consumo dos vinhos, sal e manufaturas de Portugal; assim como em Portugal se dá preferência ao açúcar, café e mais gêneros do Brasil; devendo considerar-se os dois países como se fossem unidos em território. ${ }^{43}$

Dessa forma, letrados que, a princípio, apresentavam a mesma matriz teórica, fruto que eram do mesmo ambiente ilustrado português e inspirados pelas mesmas leituras, acabavam por defender perspectivas distintas a respeito da política econômica que deveria ser adotada pela Coroa para garantir o desenvolvimento econômico e, consequentemente, a manutenção do Império. Enquanto para Silva Lisboa o livre comércio aparecia como condição essencial ao desenvolvimento do Império português, para Acúrsio das Neves, a abertura dos portos teria sido o grande responsável pela crise eco-

\footnotetext{
42 NEVES, José Acúrsio das, op. cit., 1820, p. 79.

${ }^{43}$ NEVES, José Acúrsio das. Variedades sobre objetos relativos às artes, comércio e manufaturas, consideradas segundo os princípios da economia política. Lisboa: Impressão Régia, 1814, p. 157.
} 
rev. hist. (São Paulo), n. 173, p. 253-276, jul.-dez., 2015 http://dx.doi.org/10.11606/issn.2316-9141.rh.2015.107386
Sérgio Hamilton da Silva Barra

A Impressão Régia do Rio de Janeiro e a criação do Novo Império português na América

nômica que o antigo Reino atravessava, e a manutenção do livre comércio (especialmente com a Inglaterra) impedia o desenvolvimento das manufaturas do Reino. A solução era a manutenção dos vínculos comerciais (se não exclusivos, ao menos preferenciais) entre Portugal e Brasil. Pregava Acúrsio que também Portugal, seguindo o exemplo de outros países, deveria adotar medidas que protegessem o seu comércio e indústria da concorrência estrangeira:

Não há um Estado, por mais pequeno que seja, onde não respire o ciúme contra as manufaturas estrangeiras, e se não procurem os meios de vedar a sua entrada; nós estamos em uma direção contrária e a nossa indústria é esmagada com o peso da estrangeira. ${ }^{44}$

Essa divergência entre os dois letrados não encontra a sua explicação apenas na posição geográfica que cada um ocupava com relação ao móvel centro do Império, ao contrário do que se pode pensar em um primeiro momento, uma vez que a perspectiva de Silva Lisboa encontrava seus críticos também entre letrados que, assim como ele, atuavam na Impressão Régia do Rio de Janeiro e, portanto, tinham os seus interesses vinculados à manutenção do aparelho administrativo do Império português nesse lado do Atlântico. Este foi o caso de Manuel Ferreira de Araújo Guimarães, redator de $O$ Patriota e também da Gazeta do Rio de Janeiro. ${ }^{45}$ Mas a divergência está relacionada às diferentes doutrinas econômicas que influenciaram o pensamento do reformismo ilustrado português na questão a respeito do posicionamen-

\footnotetext{
${ }^{44}$ NEVES, José Acúrsio das, op. cit., 1820, p. 136. Considerado o precursor do industrialismo em Portugal por seus biógrafos, o pensamento de Acúrsio das Neves comportava contradições como a união de uma perspectiva econômica liberal e uma concepção absolutista de poder. Mas, como explica José Luís Cardoso, essa contradição era o dilema fundamental que atravessava a sociedade portuguesa naquele momento: "o dilema de uma sociedade em que as reformas econômicas de inspiração liberal se desejam e programam sem a contrapartida de uma modificação da estrutura política do Estado absolutista cuja essência e natureza se procura perpetuar". (CARDOSO, José Luís, op. cit., 1989, p. 209).

${ }^{45}$ Em 1813, Guimarães reeditou, em O Patriota, duas memórias, datadas do final do século XVII e da primeira metade do século XVIII, de autoria de Alexandre de Gusmão e Duarte Ribeiro de Macedo, que expressavam ideias radicalmente contrárias às de Silva Lisboa a respeito de outro tema controverso com relação à política econômica da monarquia portuguesa: a concessão de privilégios para a instalação de manufaturas no Império como forma de evitar a evasão de capitais. GUSMÃO, Alexandre de. Cálculo sobre a perda do dinheiro do Reino. O Patriota: Jornal literário, político e mercantil. Rio de Janeiro: Impressão Régia, $\mathrm{n}^{\circ}$ 1, jan./fev. 1813, p. 101-107; e MACEDO, Duarte Ribeiro de. Discurso do doutor Duarte Ribeiro de Macedo sobre a introdução das artes no Reino, que escreveu sendo enviado na corte de Paris no ano de 1675. O Patriota: Jornal literário, político e mercantil. Rio de Janeiro: Impressão Régia, $\mathrm{n}^{\circ} 2$, ago. 1813, p. 41-50; n 3 , set. 1813, p. 34-49; e no 4, out. 1813, p. 29-47.
} 
to do Estado em relação à ação econômica, como explica José Luís Cardoso. Além do sistema de economia política liberal de Adam Smith, as políticas econômicas implementadas pelos administradores coloniais portugueses sofriam a influência de matrizes tais como o mercantilismo tardio, o cameralismo germânico e a fisiocracia francesa. ${ }^{46}$ Tais matrizes permitiam que letrados como Acúrsio das Neves pudessem ser, ao mesmo tempo, entusiastas declarados da política econômica pombalina e adeptos das ideias econômicas liberais de Smith, enquanto outros, tais como Silva Lisboa, consideravam todo e qualquer tipo de protecionismo um anacronismo mercantilista.

Dessa forma, os trabalhos sobre economia política produzidos por letrados portugueses ao longo das primeiras décadas do século XIX nos permitem sublinhar o papel político da Impressão Régia do Rio de Janeiro diante das tensões existentes no interior do Império português no contexto do estabelecimento da Corte na América. Partindo, muitas vezes, de um denominador comum, e sem deixar de expressar a herança do patrimônio intelectual da Ilustração portuguesa, os seus autores acabavam por defender, muitas vezes, posições distintas, e mesmo antagônicas, acerca da política econômica mais adequada para a preservação do Império português.

\section{Considerações finais}

Atuando sob o controle de um rígido aparato censório que estava a cargo da sua Junta Administrativa, e submetida ao controle da Secretaria de Estado dos Negócios Estrangeiros e da Guerra que, por sua vez, esteve sob a direção de d. Rodrigo de Sousa Coutinho até 1812, a tipografia criada por d. João se esforçou em enunciar um discurso homogêneo sobre economia política, cujo principal objetivo era justificar a nova política econômica adotada pelo príncipe regente. Ao mesmo tempo, exercendo a sua dupla função de propaganda e censura, procurava não deixar transparecer na nova Corte perspectivas antagônicas, não dando repercussão na América portuguesa às ideias divergentes. Todavia, ainda assim era possível ler na Corte discursos discordantes que, burlando a censura ou se aproveitando do seu caráter seletivo (que liberava para determinadas pessoas, de acordo com o seu ofício e posição social, a leitura de livros e autores que eram proibidos para a

\footnotetext{
${ }^{46}$ A respeito da diferença entre cada uma dessas matrizes e sua influência no pensamento econômico do marquês de Pombal e de d. Rodrigo de Sousa Coutinho, ver CARDOSO, José Luís $\&$ CUNHA, Alexandre Mendes, op. cit., 2011, p. 31-88.
} 
maioria da população), ${ }^{47}$ apontavam para as tensões surgidas da tentativa de execução do projeto político ilustrado de construção do novo Império português na América, assim como para projetos alternativos de Império.

Dessa forma, para além da heterogeneidade de assuntos abordados em suas publicações e do seu sempre ressaltado papel de introdutora da imprensa no Brasil, a Impressão Régia do Rio de Janeiro ocupou um lugar importante dentro da estrutura administrativa do Império português. Ao herdar das suas congêneres do velho Reino a função pragmática de difusão das Luzes no Império português, a nova tipografia fazia da sua função cultural uma função política, ressaltando a relação intrínseca existente entre cultura e poder nas monarquias absolutistas. Se é possível atribuir um sentido geral à sua atuação, este é o papel político que a tipografia desempenhou na legitimação e sustentação do projeto de criação de um novo Império português na América, erigido sobre a herança do patrimônio intelectual da Ilustração portuguesa.

\section{Referências bibliográficas}

BARRA, Sérgio Hamilton da Silva. Ilustração e memória: a Impressão Régia do Rio de Janeiro e o projeto do novo Império português. Tese de doutorado em História Social da Cultura, Departamento de História da PUC-Rio, 2012.

CARDOSO, José Luís. O pensamento econômico em Portugal nos finais do século XVIII 17801808. Lisboa: Estampa, 1989.

CARDOSO, José Luís \& CUNHA, Alexandre Mendes. Discurso econômico e política colonial no Império luso-brasileiro (1750-1808). Revista Tempo. Niterói, vol. 17, $\mathrm{n}^{\mathrm{o}}$ 31, 2011, p. 31-88.

DIAS, Maria Odila da Silva. Aspectos da Ilustração no Brasil. Revista do Instituto Histórico e Geográfico Brasileiro. Rio de Janeiro: Instituto Histórico e Geográfico Brasileiro, vol. 278, jan./mar. 1968, p. 105-170.

DOMINGUES, Ângela. Para um melhor conhecimento dos domínios coloniais: a constituição de redes de informação no Império português em finais dos Setecentos. História. Ciências, Saúde - Manguinhos, vol. VIII (suplemento), 2001, p. 823-838.

KIRSCHNER, Tereza Cristina. José da Silva Lisboa, visconde de Cairu: itinerários de um ilustrado luso-brasileiro. São Paulo / Belo Horizonte: Alameda / PUC-Minas, 2009.

\footnotetext{
${ }^{47}$ Luiz Carlos Villalta é quem nos chama a atenção para o caráter seletivo da censura no Império português, que estabelecia a existência do que ele denomina de uma "estamentalização-corporativização" da posse e leitura de livros. VILLALTA, Luiz Carlos. Censura literária e inventividade dos leitores no Brasil colonial. In: CARNEIRO, Maria Luiza Tucci (org.). Minorias silenciadas: História da censura no Brasil. São Paulo: EdUSP/Fapesp, 2002, p. 45 a 89.
} 
rev. hist. (São Paulo), n. 173, p. 253-276, jul.-dez., 2015 http://dx.doi.org/10.11606/issn.2316-9141.rh.2015.107386
Sérgio Hamilton da Silva Barra

A Impressão Régia do Rio de Janeiro e a criaç̃ó do Novo Império português na América

KURY, Lorelai. Homens de ciência no Brasil: impérios coloniais e circulação de informações (1780-1810). História, Ciências, Saúde - Manguinhos, vol. 11 (suplemento 1), 2004, p. 109-129.

Descrever a pátria, difundir o saber. In: KURY, Lorelai (org.). Iluminismo e Império no Brasil: O Patriota (1813-1814). Rio de Janeiro: Editora Fiocruz, 2007, p. 141 a 178.

LYRA, Maria de Lourdes Vianna. A utopia do poderoso Império. Rio de Janeiro: Sette Letras, 1994.

MATTOS, Ilmar Rohloff de. Do Império do Brasil ao Império do Brasil. In: FACULDADE DE LETRAS DA UNIVERSIDADE DO PORTO (org.). Estudos em homenagem a Luís Antonio de Oliveira Ramos. Porto: Universidade do Porto, 2004, p. 727-736.

Construtores e herdeiros: a trama dos interesses na construção da unidade política. Almanack Brasiliense. São Paulo: USP, nº 1, maio de 2005, p. 8-26.

MAXWELL, Kenneth. Marquês de Pombal: O paradoxo do Iluminismo. Rio de Janeiro: Paz e Terra, 1996.

. A geração de 1790 e a ideia do Império luso-brasileiro. In: Idem. Chocolates, piratas e outros malandros: ensaios tropicais. Rio de Janeiro: Paz e Terra, 1999. p. 157-207.

MEIRELLES, Juliana Gesuelli. Imprensa e poder na corte joanina: A Gazeta do Rio de Janeiro (1808-1821). Rio de Janeiro: Arquivo Nacional, 2008.

MORAES, Rubens Borba de. Livros e bibliotecas no Brasil colonial. São Paulo: Secretaria de Cultura, Ciência e Tecnologia, 1979.

NUNES, Maria de Fátima. Imprensa periódica científica (1772-1852): leituras de "sciencia agrícola" em Portugal. Lisboa: Estar Editora, 2001.

ROCHA, Antônio Penalves. A economia política na sociedade escravista: um estudo dos textos econômicos de Cairu. São Paulo: Hucitec, 1996.

ROCHA, Antônio Penalves (org.). José da Silva Lisboa: visconde de Cairu. São Paulo: Editora 34, 2001.

SANTOS, Nívia Pombo Cirne dos. Dom Rodrigo de Souza Coutinho: pensamento e ação político-administrativa no Império português (1778-1812). Dissertação de mestrado em História Social, Departamento de História da UFF, 2002.

SCHULTZ, Kirsten. Versalhes tropical: Império, monarquia e a corte real portuguesa no Rio de Janeiro, 1808-1821. Rio de Janeiro: Civilização Brasileira, 2008.

SCHWARCZ, Lilia Moritz. A longa viagem da biblioteca dos reis: do terremoto de Lisboa à Independência do Brasil. São Paulo: Companhia das Letras, 2002.

VILLALTA, Luiz Carlos. Censura literária e inventividade dos leitores no Brasil colonial. In: CARNEIRO, Maria Luiza Tucci (org.). Minorias silenciadas: História da censura no Brasil. São Paulo: EdUSP/Fapesp, 2002, p. 45 a 89. 